\title{
Corrigendum
}

Robert Pest

\section{Corrigendum zu: Die konsularische Unterstützung im Strafverfahren}

\author{
Aktuelle Tendenzen der höchstrichterlichen Rechtsprechung
}

DOI 10.1515/juru-2014-9056

Corrigendum zu: Robert Pest. Juli 2015. Die konsularische Unterstützung im Strafverfahren. Juristische Rundschau. Jahrgang 2015, Heft 7, Seiten 359-379 (DOI:10.1515/ juru-2015-0056):

Auf Seite 360 heißt es in der Überschrift »II. « versehentlich »Regelungsgehalt von Art. 36 WÜK und § 114 II 3 StPO«. Richtig soll es stattdessen lauten »Regelungsgehalt von Art. 36 WÜK und $\S 114$ b II 3 StPO«.

Auf Seite 362 heißt es in der Überschrift »2. « versehentlich »Verhältnis von Art. 36 WÜK zu § 114 II 3 StPO«. Richtig soll es stattdessen lauten »Verhältnis von Art. 36 WÜK zu § 114b II 3 StPO«.

Robert Pest: Der Autor ist wissenschaftlicher Mitarbeiter am Lehrstuhl für Strafrecht, Strafprozessrecht, Europäisches Strafrecht und Neuere Rechtsgeschichte von Prof. Dr. Martin Heger, HumboldtUniversität zu Berlin. 